\title{
Model of Thermal Plume above Cooking Gas Stove for Designing Ventilation
}

\author{
Yuki Shimanuki ${ }^{1}$, Takashi Kurabuchi ${ }^{2}$, Yoshihiro Toriumi ${ }^{3}$, and Yasuhisa Asawa ${ }^{1}$ \\ ${ }^{1}$ Tokyo Gas Co., Ltd, Tokyo, Japan \\ ${ }^{2}$ Department of Architecture, Faculty of Engineering, Tokyo University of Science, Tokyo, Japan \\ ${ }^{3}$ Division of Architecture, Civil and Environmental Engineering School of Science and Engineering, Tokyo Denki University, Saitama, \\ Japan
}

\begin{abstract}
A model of the thermal plume above a cooking gas stove using computational fluid dynamics (CFD) analysis was studied to predict the heat and vapor released during cooking. The combustion gas released from the burner installed in the gas stove was considered as air in which thermal energy was adjusted so that the thermal plume above the gas stove could be simulated. Therefore, the model could predict the thermal plume above the gas stove based on the capacity of the burner and pot size. For validating the simulated flow fields, the results of the velocity distributions above the gas stove calculated using CFD analysis models were compared with the results of the velocity distributions measured with particle image velocimetry (PIV). In conclusion, the analysis results were in good agreement with the measurement results. However, the velocity in the vertical direction calculated using CFD above the center of the burner was higher than the velocity measured using PIV along the axis from the center of the burner.
\end{abstract}

\section{Introduction}

Computational fluid dynamics (CFD) analysis is often used to design ventilation in commercial kitchens. The heat and vapor released during cooking negatively affect the environment in the kitchen. Therefore, appropriate ventilation must be designed to balance environmental degradation with efficient utilization of energy. For designing appropriate ventilation, CFD analysis can be used to calculate the capture efficiency of the hood for different types of kitchen appliances and different disturbance conditions.

Several CFD models for calculating the capture efficiency of the exhaust gas released from the gas stove have been studied [1-3]. In these models, the measured data of the velocity distribution corresponding to the size of each burner and pot is needed to set the boundary conditions. Omori et al. proposed the exhaust gas plume model [4]. The combustion gas released from the burner installed in the gas stove was considered as air in which thermal energy was adjusted so that the thermal plume above the gas stove could be simulated. Therefore, the model could predict the thermal plume above the gas stove without the measured data of velocity distributions. However, it is not verified whether the velocity distribution corresponding to the pot shape can be simulated.

Hence, in this study, a model of the thermal plume above a cooking gas stove based on the Omori's model [4] was developed for different pot diameters. For validating the simulated flow fields, velocity distributions above a commercial cooking gas stove were measured using particle image velocimetry (PIV). A gas stove equipped with a $14.5-\mathrm{kW}$ burner was placed in a test room composed of a ventilation system that guaranteed undisturbed flow from the system. The cooking mode was evaluated with boiling water in the pot. The results of velocity distributions above the gas stove calculated using CFD analysis models were compared with the results of velocity distributions measured using PIV. In conclusion, the analysis results showed good agreement with the measurement results.

\section{Nomenclature}

$Q_{i n}$ : Heating power of the burner

$Q_{t r n}$ : Heat transfer through the pot

$Q_{t a b}:$ Heat transfer through the gas stove

$Q_{e x}$ : Heat transfer across the top of the pot

$Q_{\text {eff }}$ : Heat transfer through the pot

$Q_{\text {pan }}:$ Radiant heat transfer energy of the pot

$\eta$ : Thermal efficiency of the gas stove

$A_{\text {pan }}$ : Surface area of the pot

$\varepsilon_{l}$ : Emissivity of the pot

$\varepsilon_{2}$ : Emissivity of the wall

$\sigma$. Stefan-Boltzmann constant $\left(5.67 \times 10^{-8} \mathrm{Wm}^{-2} \mathrm{~K}^{-4}\right)$

$T_{p}$ : Surface temperature of the pot

$h_{\text {tab: }}$ : Heat transfer coefficient

$A_{t a b}$ : Surface area of the top of the gas stove

$t_{t a b}$ : Surface temperature of the top of the gas stove

$t_{0}$ : Room temperature

\footnotetext{
*Yuki Shimanuki: n-yuki@tokyo-gas.co.jp
} 
$d t$ : difference between combustion gas temperature and room temperature

$d$ : Diameter of the pot

\section{Analysis methods used in CFD}

\subsection{Configuration of calculated field}

Figure 1 shows the calculation domain for the CFD simulation. The pot and gas stove were set in the center of the calculation domain. We used half of the area as the calculation domain because the two halves of the calculation area were symmetrical. Air was supplied from the floor and was exhausted from the ceiling. The dimensions of the pot and the gas stove are shown in Figure 2. We used three pot diameters of $330 \mathrm{~mm}, 390$ $\mathrm{mm}$, and $440 \mathrm{~mm}$ to evaluate whether the model could estimate the effect of pot size on the thermal plume above the gas stove.

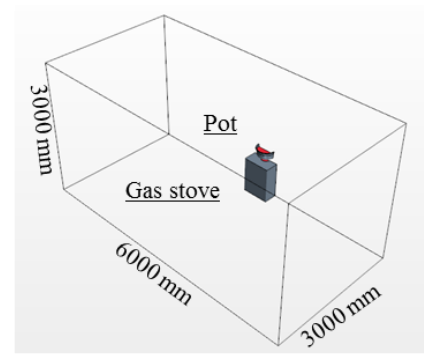

Fig. 1. Calculation Domain for CFD Analysis.

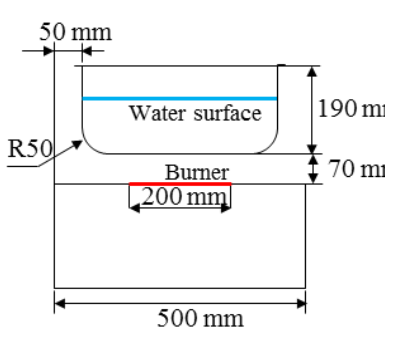

Fig. 2. Dimensions of Pot and Gas Stove.

\subsection{Model of combustion gas}

We considered the gas released from the gas stove as air in which thermal energy was adjusted to simulate the thermal plume above the gas stove.

Figure 3 shows the model used for representing the combustion gas. The natural gas passing through the burner burns transmits heat to the pan and gas stove and flows over the pan.

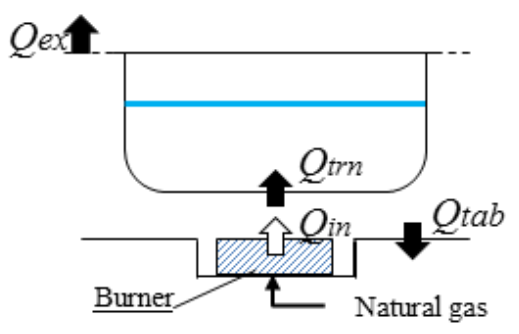

Fig. 3. Schematic of the Model.

The thermal energy of the air supplied from burner was adjusted to match the heat flux across the top of the pot. The heat flux across the top of the pot can be described as

$$
Q_{e x}=Q_{i n}-Q_{t r n}-Q_{t a b}
$$

Heat transfer across the top of the pot is described as heat transfer through the pot and radiant heat transfer energy as

$Q_{e x}=Q_{i n}-Q_{e f f}-Q_{p a n}-Q_{t a b}$.

Heat transfer through the pot, radiant heat transfer energy of the pot, and heat transfer through the gas stove can be described as follows:

$Q_{\text {eff }}=\eta Q_{\text {in }}$

$Q_{\text {pan }}=A_{\text {pan }} \varepsilon_{1} \varepsilon_{2} \sigma 4 T_{p}$

$Q_{t a b}=h_{t a b} A_{t a b}\left(t_{t a b}-t_{0}\right)$

Table 1 presents the analysis cases. Each parameter was determined in correspondence with the gas stove used for measurements in the PIV tests and heating value of natural gas in Japan. The heating thermal efficiency of the gas stove was measured using the pot with diameters of $330 \mathrm{~mm}, 390 \mathrm{~mm}$, and $440 \mathrm{~mm}$ in advance.

Table 1. Analysis cases

\begin{tabular}{|c|c|c|c|c|}
\hline$d$ & $\mathrm{~mm}$ & 330 & 390 & 440 \\
\hline$Q_{e x}$ & $\mathrm{~W}$ & 7840 & 6570 & 5710 \\
\hline$Q_{\text {in }}$ & $\mathrm{W}$ & 13900 & 13000 & 13000 \\
\hline$Q_{\text {eff }}$ & $\mathrm{W}$ & 4460 & 5690 & 6190 \\
\hline$Q_{\text {pan }}$ & $\mathrm{W}$ & 193 & 247 & 297 \\
\hline$Q_{\text {tab }}$ & $\mathrm{W}$ & 460 & 460 & 460 \\
\hline$\eta$ & $\%$ & 31.4 & 39.5 & 43.0 \\
\hline$A_{\text {pan }}$ & $\mathrm{m}^{2}$ & 0.282 & 0.352 & 0.414 \\
\hline$A_{\text {tab }}$ & $\mathrm{m}^{2}$ & 1.00 & 1.00 & 1.00 \\
\hline$\varepsilon_{1, \varepsilon_{2}}$ & - & 0.900 & 0.900 & 0.900 \\
\hline$h_{\text {tab }}$ & $\mathrm{Wm}^{-2} \mathrm{~K}^{-1}$ & 10 & 10 & 10 \\
\hline$T_{p}$ & ${ }^{\circ} \mathrm{C}$ & 100 & 100 & 100 \\
\hline$t_{t a b}$ & ${ }^{\circ} \mathrm{C}$ & 70 & 70 & 70 \\
\hline$t_{0}$ & ${ }^{\circ} \mathrm{C}$ & 24 & 24 & 24 \\
\hline
\end{tabular}

\subsection{Boundary conditions}

Table 2 lists the boundary conditions. We set a boundary condition of floor as velocity inlet to stabilize the calculation. The boundary condition for the burner was set based on the model of the combustion gas.

Table 2. Boundary conditions

\begin{tabular}{|c|c|}
\hline Boundary & Type \\
\hline Floor & $\begin{array}{c}\text { Velocity inlet } \\
\text { (Temperature: } 24.0^{\circ} \mathrm{C}, \text { Velocity: } 0.0400 \mathrm{~m} / \mathrm{s}, \\
\text { Density: } 0.950 \mathrm{~kg} / \mathrm{m}^{3}, \text { Material: Air) }\end{array}$ \\
\hline Ceiling & $\begin{array}{c}\text { Pressure outlet } \\
\text { (Pressure: } 0.00 \mathrm{~Pa})\end{array}$ \\
\hline Wall & Slip wall, Adiabatic \\
\hline Burner & $\begin{array}{c}\text { Velocity inlet } \\
\text { (Temperature: } 100^{\circ} \mathrm{C}, \text { Velocity: } 2.87 \mathrm{~m} / \mathrm{s}, \text { Density: } \\
0.950 \mathrm{~kg} / \mathrm{m}^{3}, \text { Material: Air) }\end{array}$ \\
\hline $\begin{array}{c}\text { Velocity inlet } \\
\text { Water }\end{array}$ & $\begin{array}{c}\text { (Temperature: } 100.0^{\circ} \mathrm{C}, \text { Water vapor generation } \\
\text { rate: } 0.0330 \mathrm{~m} / \mathrm{s}, \text { Density: } 0.598 \mathrm{~kg} / \mathrm{m}^{3}, \text { Material: } \\
\left.\mathrm{H}_{2} \mathrm{O}\right)\end{array}$ \\
\hline $\begin{array}{c}\text { Surface of } \\
\text { the pot }\end{array}$ & $\begin{array}{c}\mathrm{Wall} \\
\left(\mathrm{Temperature:} 100.0{ }^{\circ} \mathrm{C}\right)\end{array}$ \\
\hline
\end{tabular}




\subsection{Code and mesh}

Table 3 gives the analysis conditions. The mesh size was $10 \mathrm{~mm}$, and the number of cells was 560,000 .

Table 3. Analysis conditions

\begin{tabular}{|c|c|}
\hline Software & Star-CCM 12.01 \\
\hline Turbulence & Standard k- $\varepsilon$ Model \\
\hline Density & Ideal gas \\
\hline Algorism & Steady State \\
\hline
\end{tabular}

\section{Measurement methods for velocity distributions and thermal distributions}

\subsection{Test room for measurement}

A gas stove $(900 \mathrm{~mm} \times 600 \mathrm{~mm}$ with a height of $800 \mathrm{~mm}$; RSB-096SV/RINNAI) was set at the center of the test room. The convection plumes from a $14.5-\mathrm{kW}$ burner were studied. The cooking mode of the stove was set with boiling water in pots with different diameters of $330 \mathrm{~mm}$, $390 \mathrm{~mm}$, and $440 \mathrm{~mm}$. For velocity distributions measurement, two pot diameters of $330 \mathrm{~mm}$ and $390 \mathrm{~mm}$ were used. For thermal distributions measurement, three pot diameters $330 \mathrm{~mm}, 390 \mathrm{~mm}$, and $440 \mathrm{~mm}$ were used.

\subsection{Measurement methods for PIV test}

Figure 4 shows the schematic of the methods used to measure the velocity distributions. Two different regions were set for PIV measurements to reveal the detailed development of the thermal plume. A vertical crosssection, two-dimensional PIV test was performed. The shooting area was $600 \mathrm{~mm} \times 800 \mathrm{~mm}$. For a horizontal cross-section at a height of $1000 \mathrm{~mm}$ from the top of the gas stove, a stereo PIV test was performed. The plume in the region directly affects the capture efficiency because ventilation hoods for gas stoves are set at this height in commercial kitchens. Therefore, we measured the detailed velocity composition in this region. The shooting area was $600 \mathrm{~mm} \times 800 \mathrm{~mm}$. The velocity plumes were fully developed at a height of $1000 \mathrm{~mm}$ from the top of the gas stove. The frame straddling technique was used for measurement. A double-pulse laser (LS-2145PIV;

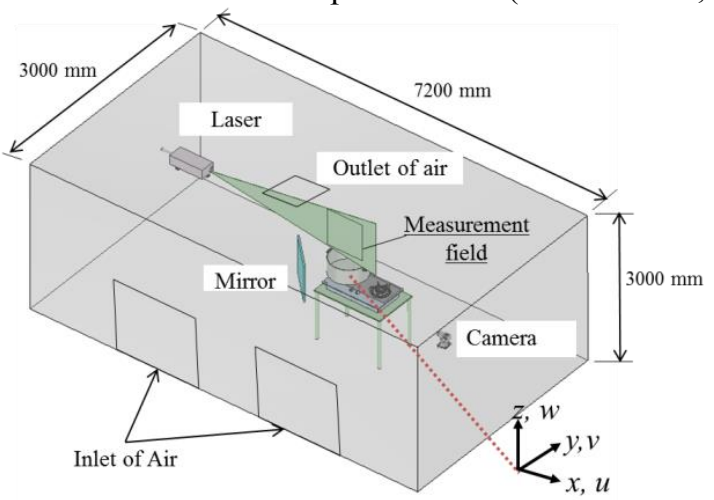

(a) Two-dimensional PIV test for vertical cross section

Fig. 4. Schematic of methods used to measure velocity distributions with PIV ( $u$ is the velocity component in $x$ direction, $v$ is the velocity component in $y$ direction, and $w$ is the velocity component in $z$ direction).
LOTIS TII, Minsk, Belarus) and double-shutter camera (FtrNPC; Flowtech Research Inc., Yokohama, Japan) equipped with a 50-mm lens (AF Micro-Nikkor; Nikon, Tokyo, Japan) were set up. The laser and camera were synchronized with a pulse generator (VSD2000; Flowtech Research Inc.) and software (FtrPIV Ver.3.2; Flowtech Research Inc.) to record matched pairs of particle images. The laser frame straddle time was adjusted to ensure that the tracer particle moved no more than $5 \mathrm{px}$ during this time; consequently, it was set to $1300 \mu$ s for the vertical cross section and $500 \mu$ s for the horizontal cross section. The laser-pulse frequency was $10 \mathrm{~Hz}$, which was the maximum value permitted by the device. The statistical data comprised 2000 images from the two-dimensional PIV test and 4000 images from the stereo PIV test. The result was arranged into a time-averaged flow field. The airflow was supplied from the displacement ventilation system (FLOORMASTER; Takasago Thermal Engineering Co., Ltd., Tokyo, Japan), which guaranteed an undisturbed convection flow from the ventilation system. Olive oil mist was selected as the tracer particle. Olive oil mist particles were released from three oil mist generators in the cooking mode.

\subsection{Measurement methods for thermal distributions}

The difference between the plume temperature at a height of $1000 \mathrm{~mm}$ from the top of the gas stove and room temperature was measured with hot wire anemometers. The measurement was not performed simultaneously with PIV because the anemometers would disturb the fluid velocity. The flow rate of the input gas was measured with a mass flow meter (CMG500; Azbil, Fujisawa).

\section{Results and discussion}

\subsection{Comparison of the CFD results and experimental results}

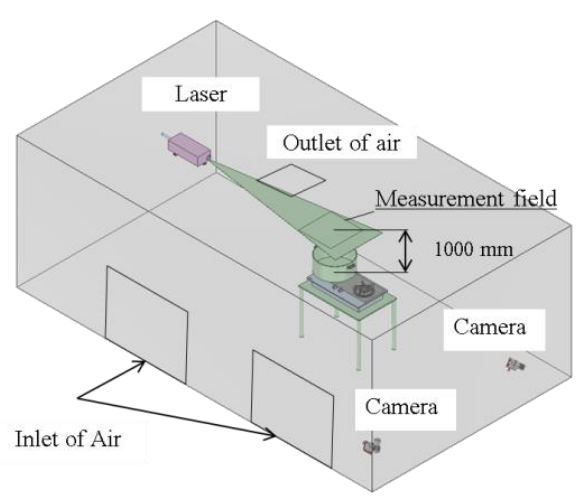

(b) Stereo PIV test for horizontal cross section 


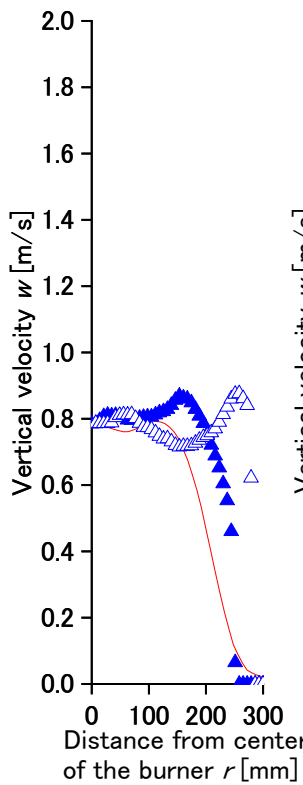

(a) $\mathrm{z}=500 \mathrm{~mm}$

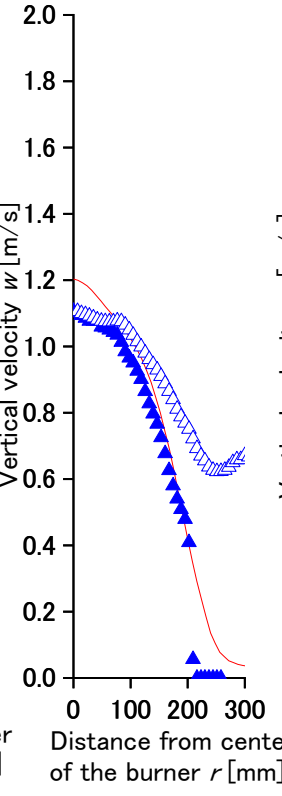

(b) $\mathrm{z}=600 \mathrm{~mm}$

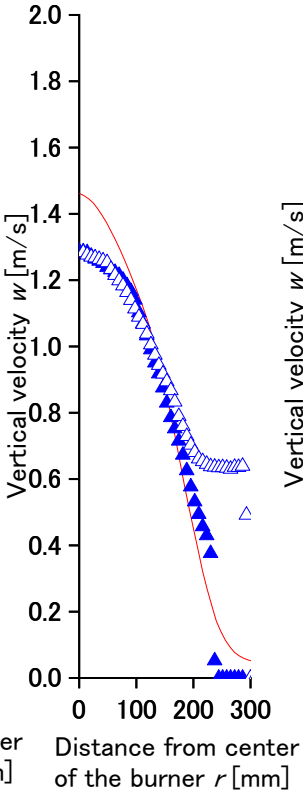

(c) $\mathrm{z}=700 \mathrm{~mm}$

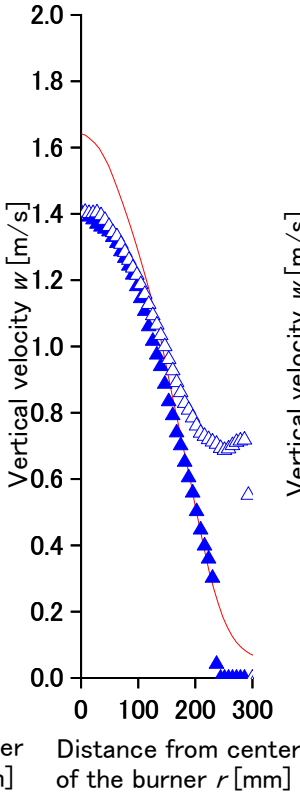

(d) $\mathrm{z}=800 \mathrm{~mm}$

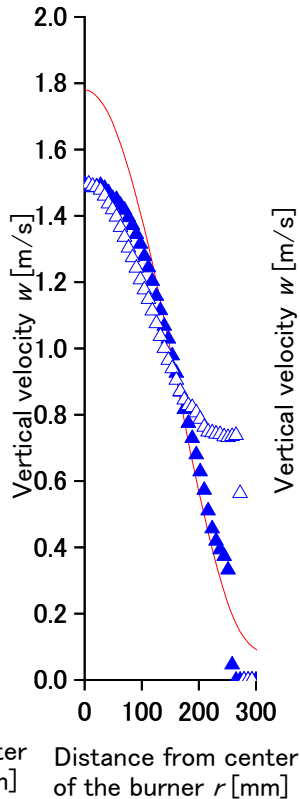

(e) $\mathrm{z}=900 \mathrm{~mm}$

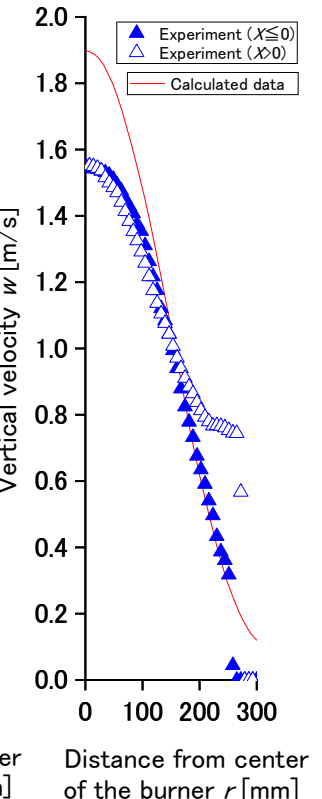

(f) $\mathrm{z}=1000 \mathrm{~mm}$

Fig. 5. Vertical velocity distributions at heights up to $1000 \mathrm{~mm}$ from the top of the gas stove with the 390-mm-diameter pot (the filled triangles indicate experimental results from the left half of the image; the unfilled triangles indicate experimental data from the right half of the image, and the solid line represents calculated results).

Figure 5 shows a comparison of calculated results and experimental results of the vertical velocity distributions at heights up to $1000 \mathrm{~mm}$ from the top of the gas stove. The calculated results were in good agreement with the measurement results. However, the velocity in the vertical direction calculated by CFD above the center of the burner was higher than the velocity measured by PIV along the axis from the center of the burner. Kiyosuke et al. suggested that standard k- $\varepsilon$ models predict the insufficient diffusion in the buoyant plume, so the simulated capture efficiency of exhaust gas released from the gas stove tends to be overestimated [5]. Therefore, investigating the turbulence model for predicting the thermal plume is necessary in future works, to predict the capture efficiency accurately.

\subsection{The velocity and temperature distributions above the pot}

Figure 6 shows a comparison of the calculated results and experimental results for the temperature rise and velocity distributions with different diameters of the pot. The results were compared at a height of $1000 \mathrm{~mm}$ from the top of the gas stove. The ventilation hood is generally installed at this level. Thus, the thermal plume at this

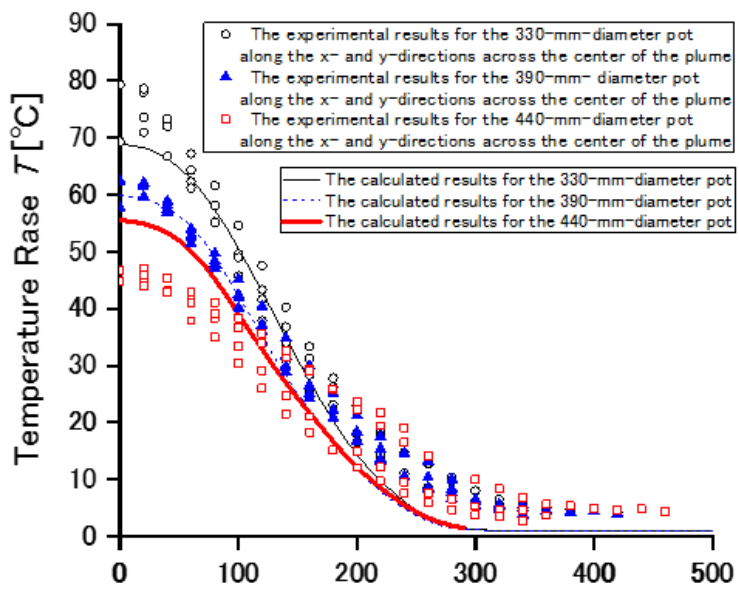

Distance from the center of the plume $r$ ' $[\mathrm{mm}]$

(a) Temperature rise distributions at a height of $1000 \mathrm{~mm}$ from the top of the gas stove

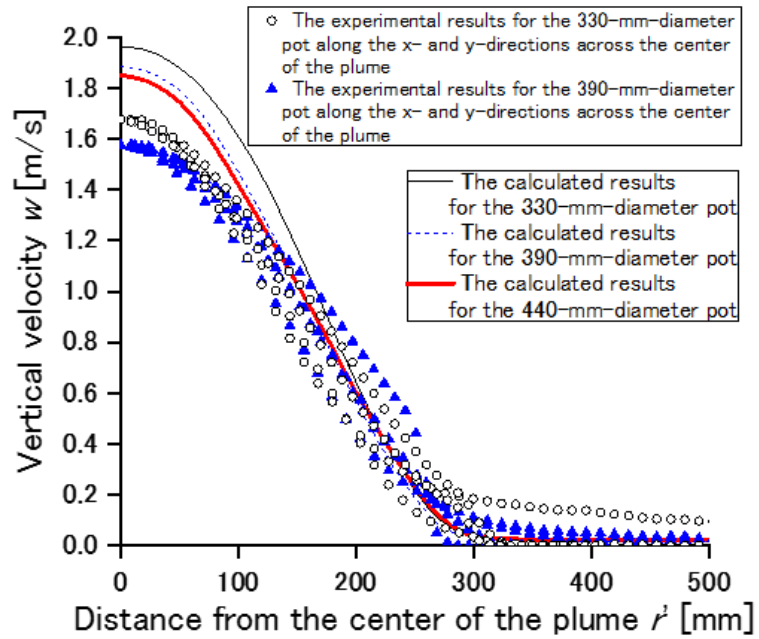

(b) Vertical velocity distributions at a height of $1000 \mathrm{~mm}$ from the top of the gas stove

Fig. 6. Comparison of calculated results and experimental results of the velocity distributions and temperature rise with different diameters of the pot. 
height affects the capture efficiency. The profile of the temperature rise calculated using CFD agreed with the profile obtained experimentally regarding the effect of the diameter of the pot on the thermal plume. However, the velocity in the vertical direction calculated using CFD above the center of the burner was also higher than the velocity measured using PIV along the axis from the center of the burner.

\section{Conclusions}

A model of the thermal plume above the cooking gas stove using CFD analysis was studied based on the present study to predict the heat and vapor released during cooking.

The analysis results calculated were in good agreement with the measurement results obtained via the PIV test. However, the velocity along the vertical direction calculated using CFD above the center of the burner was higher than the velocity measured using PIV along the axis from the center of the burner. Therefore, investigating the turbulence model for predicting the thermal plume is necessary in future works to predict the capture efficiency accurately.

\section{Acknowledgements}

This study was made possible by the technical support from Dr. Toshiaki Omori of the University of Tokyo. We would also like to thank Reo Murakami and Masaru Shimokawa of the Fundamental Technology Research Institute of Tokyo Gas Co., Ltd for their help with the simulation. Moreover, we would like to thank Flowtech Research Inc., Yokohama, Japan, who conducted the examination of PIV test.

\section{References}

1. Y. Kondo, Y. Abe, A. Miyafuji, Y. Aizawa, K. Akagi, J. Environ. Eng. 731383 (2008).

2. T. Momose, T. Yamanaka, H. Kotani, A. Yamamoto, J. Environ. Eng. 68, 49 (2003).

3. J. Sakaguchi et al. Summaries of technical papers of Annual Meeting of AIJ. D-2, 673 (2008).

4. T. Omori, Y. Shimanuki, M. Aibara, A. Okuda, Trans. SHASE, 13 (2013).

5. H. Kiyosuke, T. Kurabuchi, Y. Toriumi, Y. Shimanuki, Y. Asawa, Trans. SHASE, 49 (2018). 